\title{
Cultura urbana desde el habitar en la zona costanera del Departamento de Córdoba-Colombia
}

\author{
Cultura urbana de vivência na zona costeira do Departamento de Córdoba- \\ Colômbia
}

Urban culture from living in the coastal zone of the Department of CórdobaColombia

\author{
Arney Alfonso Vega Martínez[a] (D), Efraín de Jesus Hernández Buelvas[a] (D) \\ Nataliya Barbera Alvarado[a] (D), Emilio Francisco Flórez Ruíz[a] (D)
}

[a] Universidad del Sinú, Facultad de Ciencias Humanas, Arte y Diseño, Montería, Colombia

Cómo citar: Vega Martínez, A. A., Hernández Buelvas, E. J., Barbera Alvarado, N., \& Flórez Ruíz, E.F. (2021). Cultura urbana desde el habitar en la zona costanera del Departamento de Córdoba-Colombia. urbe. Revista Brasileira de Gestão Urbana, 13, e20190370. https://doi.org/10.1590/2175-3369.013.e20190370

\section{Resumen}

Las zonas costeras son espacios naturales con un alto potencial económico y turístico por su salida al mar; sin embargo, los municipios del Departamento de Córdoba ubicados en estos ecosistemas poseen una medición de desempeño financiero y administrativo bajo, debido a las dificultades que presentan para movilizar recursos propios y gestionar el ordenamiento territorial. En este sentido, se analiza la relación ciudad-ciudadano que se establece en los procesos de construcción urbana en dos municipios costeros del departamento desde el habitar como diagnóstico de las necesidades urbanas de estos lugares. Se abordó desde un enfoque mixto con diseño explicativo secuencial y se aplicó la encuesta de imaginarios urbanos con preguntas de naturaleza subjetiva sobre el sentir-pensar de la población en su territorio. Los resultados permiten afirmar que los nichos estéticos en ambos municipios están adecuados por sus habitantes entre lo que les gusta (playa-potencial turístico) y lo que les desagrada (déficit de infraestructura y servicios públicos) del lugar donde se encuentran arraigadas sus prácticas socioculturales, económicas y políticas. Teniendo en cuenta que los procesos de territorialización en esta región han sido lentos, se requiere de una gestión urbana tendiente a mejorar la calidad de vida de los habitantes en su entorno.

Palabras clave: Zona costera. Territorio. Cultura urbana. Habitar. Nicho urbano.

\section{Resumo}

As zonas costeiras são espaços naturais com um elevado potencial econômico e turístico por causa de sua saída para o mar. No entanto, os municípios do Departamento de Córdoba localizados nesses ecossistemas possuem uma medição de desempenho financeiro e administrativo baixo em razão das dificuldades que apresentam para mobilizar recursos próprios e gerenciar o ordenamento territorial. Neste sentido, analisa-se a relação cidade-cidadão que se estabelece nos processos de construção urbana em dois municípios costeiros do Departamento a partir da vivência como diagnóstico das necessidades urbanas

AAVM es licenciado em Ciências Sociales, magíster en Estudios Políticos, docente investigador, e-mail: arneyvega@unisinu.edu.co EJHB es biólogo, magíster em biotecnologia, docente investigador, e-mail: efrainhernandezb@unisinu.edu.co

NBA es licenciada en Educación Mención Lengua, doctora en Planificación y Gestión del Desarrollo Regional, docente investigador, e-mail: nataliaberbera@unisinu.edu.co

EFFR es arquitecto, especialista en Conservación y Restauración del Patrimonio Arquitectónico, decano, e-mail: eflorez@unisinu.edu.co 
desses lugares. Fez-se uso de uma abordagem mista com desenho explicativo sequencial e aplicou-se a pesquisa de imaginários urbanos com perguntas de natureza subjetiva sobre o sentir-pensar da população em seu território. Os resultados permitem afirmar que os nichos estéticos em ambos os municípios são adequados por seus habitantes entre o que eles gostam (praia-potencial turístico) e o que eles não gostam (déficit de infraestrutura e serviços públicos) do lugar onde se encontram enraizadas as suas práticas socioculturais, econômicas e políticas. Tendo em conta que os processos de territorialização nessa região têm sido lentos, é necessária uma gestão urbana visando melhorar a qualidade de vida dos habitantes no seu ambiente.

Palavras-chave: Zona costeira. Território. Cultura urbana. Habitar. Nicho urbano.

\section{Abstract}

Coastal areas are natural areas with a high economic and tourist potential due to their outlet to the sea. However, the municipalities of the Department of Cordoba located in these ecosystems have a low financial and administrative performance measurement due to the difficulties they present in mobilizing their resources and managing land management. In this sense, we analyze the city-citizen relationship established in the processes of urban construction in two coastal municipalities of the department from the dwelling as a diagnosis of the urban needs of these places. It was approached from a mixed approach with sequential explanatory design and applied the survey of urban imaginaries with questions of subjective nature on the feeling-thinking of the population in their territory. The results allow us to affirm that the aesthetic niches in both municipalities are suitable for their inhabitants between what they like (beach-tourist potential) and what they dislike (lack infrastructure and public services) the place where their socio-cultural, economic, and political practices are rooted. Given that the processes of territorialization in this region have been slow, urban management is required to improve the quality of life of the inhabitants in their environment.

Keywords: Coastal zone. Territory. Urban culture. Inhabit. Urban niche.

\section{Introducción}

En la actualidad, hablar de lo urbano es hacer referencia a los procesos socioculturales, económicos, políticos y territoriales en torno a los colectivos que hacen uso de las ciudades, las cuales se asumen como un espacio que adquiere valores, identidades e imaginarios construidos históricamente mediante la forma en que se habita e intenta habitar, por lo que constituye un espacio transformado permanentemente y en constante socialización donde se dirimen disputas y tensiones por la definición de sentidos, pues es un espacio político recorrido por múltiples discursos (Gravano, 2016).

En este sentido, lo urbano está formado por un conflicto permanente entre el plano existencial, la necesidad de orden de los actores sociales que habitan la ciudad y la participación ciudadana; por lo que se considera una manifestación cultural que se relaciona con la dimensión histórica, política y social que se ve reflejada en las prácticas cotidianas compartidas socialmente. Esta mirada pone al descubierto la configuración de diversas ciudades que confluyen en el espacio físico, donde no solo se encuentra la delimitada por los urbanistas y planificadores sino aquellas que producen y revelan la topología simbólica y los territorios imaginarios construidos por quienes hacen uso permanente de la ciudad (Silva, 2000), a partir de los actos del habitar que producen socialmente el espacio, esto es, el territorio.

Ahora bien, esta perspectiva fricciona con el común denominador de los problemas de las ciudades que se centra en proyecciones urbanas ideadas bajo políticas con intereses propios, que responde a un entorno físico que necesita transformarse, casi siempre a espaldas de las verdaderas necesidades del ciudadano quien no solo vive en la ciudad, sino que también la produce, la goza, la sufre, la lucha, la 
reivindica en lo que hace de manera cotidiana (Hernández Araque, 2016). Visto así, se habla de ciudades configuradas desde un plano subjetivo mediante mecanismos psicológicos interactivos entre colectividades ciudadanas que la convierten en un efecto imaginario de quienes la habitan y que marcan sus comportamientos o reacciones como ciudadanos (Silva, 2004) a la hora de definir, ordenar y controlar el espacio habitado o territorio.

Esta perspectiva orienta un nuevo urbanismo a partir del imaginario ciudadano, esto es, un urbanismo participativo como forma de gestión urbana que proyecte soluciones inmediatas e importantes para el individuo que requiere ser vinculado en la construcción del espacio urbano en el que se desenvuelve a diario (Hernández Araque, 2016), el cual lejos de ser diáfano es producto de la apropiación y valoración simbólica e instrumental asignada por los seres humanos que lo idealizan de acuerdo a sus anhelos, estrategias de supervivencia y el alcance de sus posibilidades sociales de realización como personas (Rionda, 2008; Vega Martínez et al., 2019a).

Frente a esto, el departamento de Córdoba en la región Caribe colombiana viene experimentando un acelerado crecimiento demográfico urbano que refleja una tendencia a nivel mundial y que ha incrementado los procesos de urbanización, que, a su vez, han suscitado problemáticas de orden social, cultural y ambiental a partir de la apropiación indebida del espacio público, en el marco de un desarrollo industrial con impacto en la sostenibilidad y los cambios en la cultura y/o imaginarios de ciudad en las zonas urbanas del mismo departamento, generando fricciones entre el nuevo orden espacial y simbólico previsto en los proyectos urbanos y las prácticas ciudadanas instituyentes para acceder, usar y adecuar/representar (territorializar) la ciudad con base en sus necesidades e intereses como persona.

Estas tensiones son producto de los procesos de globalización contextualizados en los espacios urbanos del departamento que, en vez de promover la integración urbana y la inclusión social de acuerdo con sus fortalezas y características territoriales, acentúan la dificultad para la prestación efectiva de servicios públicos, el aumento del desempleo y la informalidad económica, la ejecución de proyectos de inversión, entre otros. Según el informe de Gobernabilidad local en el departamento de Córdoba realizado por Tuirán et al. (2018), con excepción de la capital Montería considerada como el principal foco de desarrollo urbano y lugar de acopio para las distintas actividades intermunicipales dentro de un subsistema en el suroeste de la Región Caribe Colombiana, la mayoría de las entidades territoriales se caracterizan por presentar una medición de desempeño financiero y administrativo en la gestión del territorio municipal medio y bajo, proyectando un rezago en su parte urbana derivado de la deficiente movilización y gestión de recursos en la mayoría de los municipios cordobeses.

Una de estas zonas es la subregión Costanera que está integrada por los municipios de San Antero, San Bernardo del Viento, Moñitos, Puerto Escondido, Los Córdobas, los cuales a pesar del alto potencial económico y turístico por su ubicación geográfica privilegiada al contar con salida al mar, poseen una medición de desempeño municipal baja producto de las dificultades en el componente de movilización de recursos y gestión de ordenamiento territorial, exceptuando el municipio de San Antero quien ha demostrado en los últimos años un comportamiento distinto dentro de su grupo (Tuirán et al., 2018).

En este sentido, resulta interesante analizar la relación ciudad-ciudadano que se establece en los procesos de construcción urbana en los municipios del Departamento de Córdoba, teniendo en cuenta que estos se encuentran en un proceso dinámico de transformación en lo social, cultural, económico y político. De ahí la importancia de desarrollar estudios sobre el senti-pensar del ciudadano en sus vivencias al interior de la urbe desde sus convicciones socioculturales y las apropiaciones que hace del espacio urbano, con el propósito de tener los elementos necesarios para la identificación de nuevas concepciones con relación a los modos de habitar que puedan ser utilizadas como diagnóstico de las necesidades de la ciudad y del ciudadano, teniendo en cuenta que son estos los principales beneficiados o afectados por los procesos de urbanización que transforman, desarrollan y generan nuevas dinámicas en el entorno en el que se desenvuelven. 


\section{El territorio como producción social del habitar}

Las zonas costeras son espacios naturales que se caracterizan por la polifuncionalidad para la vida humana, lo que los hace susceptibles de ser urbanizados produciendo formas específicas de interacción entre sociedad y medio ambiente, esto es, modos de vida urbana que hacen de las líneas costeras una urdimbre territorial de relaciones complejas entre la tierra firme y los cuerpos de agua, toda vez que en el contexto de la globalización plantea desafíos en términos de desarrollo sostenible que permitan vivir y realizar actividades productivas asociadas al potencial estratégico, paisajístico y de uso portuario/marítimo (Martí-Ciriquián \& García-Mayor, 2018; Rubilar, 2015).

Diversos estudios señalan que actualmente estos espacios se encuentran en profundos procesos de transformación territorial y crecimiento urbano debido al desarrollo turístico, la ejecución de proyectos inmobiliarios y la construcción de centros productivos de extracción de recursos marítimos, que friccionan con las formas del habitar de las comunidades asentadas en las zonas costeras. Por ejemplo, el trabajo de Álvarez Abel \& Ther Ríos (2016) pone en evidencia la desaparición de las cosmovisiones sobre las prácticas asociadas a sistemas tradicionales de administración local que aplicaban las poblaciones costeras del Mar Interior en Chiloé en Chile para acceder a los espacios costeros y proveerse de especies alimenticias propias de estos lugares, que se encuentran en transformación a causa de la instalación de la empresa privada en sus territorios, provocando una escasez de alimentos, conflictos entre humanos y problemas medioambientales que requieren del enriquecimiento cultural de políticas ligadas al uso y acceso del borde costero claramente definidas.

Sin embargo, para Hidalgo et al. (2016) algunas comunidades que habitan los bordes costeros han logrado resistir al desarrollo de proyectos inmobiliarios que afectan a las comunidades de propietarios de estos lugares, a través de la organización social permanente reflejada en las juntas de vecinos o agrupaciones ciudadanas que han renunciado a las acciones de intervención violenta y mediante la vía judicial aprovechan la debilidad de los instrumentos de planificación territorial local que se alejan de las necesidades de los ciudadanos, quienes no están dispuestos a modificar las condiciones que los llevó a establecerse en esos lugares por causa de los actores inmobiliarios.

Por su parte, Martínez et al. (2016) analizaron los patrones espaciales del crecimiento urbano sobre las principales geoformas costeras en un lugar ribereño del río Biobío en Chile, teniendo en cuenta que la antropización por urbanización en estos lugares constituye uno de los procesos de mayor impacto sobre el sistema natural de la planicie litoral de la zona, el cual evidencia una forma de crecimiento lineal y fragmentado basado en proyectos inmobiliarios que proyectan una insostenibilidad urbana al desconocer los procesos históricos que se relacionan con los espacios costeros, donde las prácticas territoriales han reducido la distancia de entre estos asentamientos y el centro urbano de Concepción en la Región del Biobío, mediante el fenómeno de la conurbación.

El estudio de Martí-Ciriquián \& García-Mayor (2018) proporciona un análisis de los procesos de renovación urbana en ciudades costeras españolas en torno a proyectos de regeneración de frente marítimos y fluviales, lo cual ha significado no solo la transformación física del lugar, sino un progresivo cambio de percepción en los habitantes sobre su ciudad, esto es, en la forma de vivir y visitar la ciudad, generando una serie de fricciones sociales que se caracterizan por la obsolescencia de las actividades/usos que históricamente constituían sus espacios y la desconexión con los tejidos urbanos colindantes. Un trabajo similar es el de Guerrero Valdebenito \& Alarcón Rodríguez (2018), quienes exploraron las tensiones que subyacen a la relación entre la pesca artesanal a pequeña escala y los proyectos de infraestructura portuaria y desarrollo urbano en sistemas urbanizados de los asentamientos litorales en Chile conocidos como Caletas, en los que se encuentran amenazadas las prácticas socioculturales, económicas y de habitabilidad tradicionales.

En conjunto, los estudios anteriores reflejan formas diferenciadas de producción social del espacio en este tipo de zonas que se encuentran en constante tensión entre la habitabilidad tradicional y la 
transformación urbanística en torno al turismo ${ }^{1}$, el sector inmobiliario y la industria portuaria-marítima; definiendo modos de vida urbana que obedecen a la existencia de un espacio que es orgánico al acto mismo de habitar, por lo que se constituye, según Lefebvre \& Lorea (2013), en el horizonte donde se sitúan, organizan, relacionan y viven los individuos. Desde esta perspectiva, para Santos (2000) el espacio es contenedor de sistemas de objetos naturales (paisaje) y es el contenido de sistemas de acciones/prácticas/experiencias sociales que se producen en él a través de formas específicas que pueden no ser originariamente geográficas, pero terminan por adquirir una expresión territorial (hábitat como espacio social) que se deriva del habitar, esto es, de los usos y percepciones en el espacio habitado que configuran ciudades subjetivas (ver Figura 1).

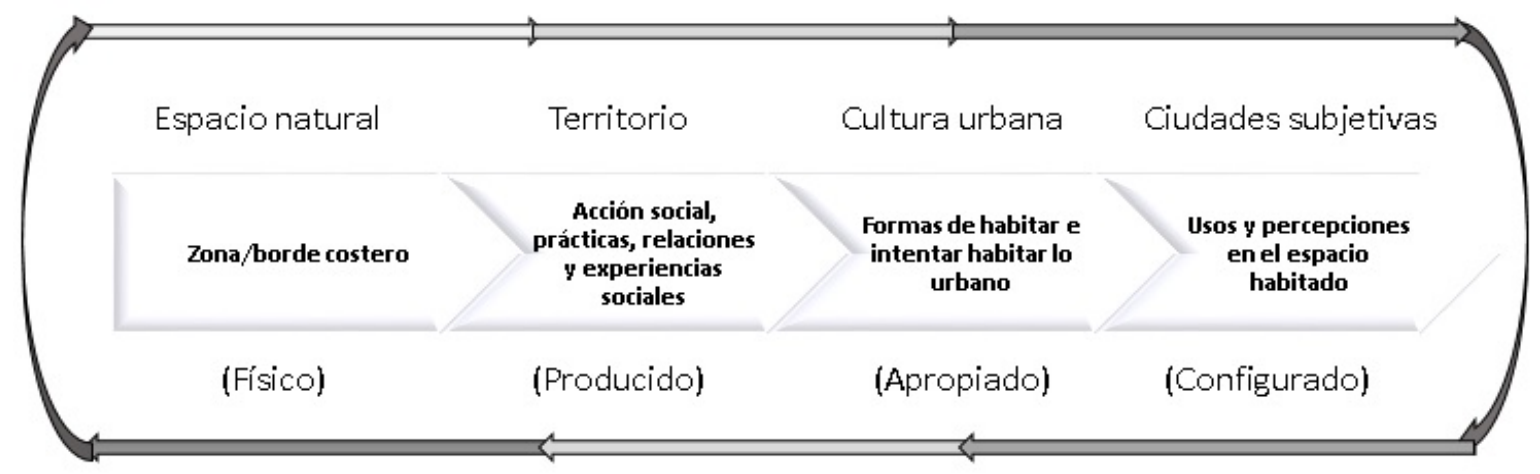

Figura 1 - Dinámica del territorio como producción social del habitar. Fuente: Elaboración propia (2019).

Teniendo en cuenta lo anterior, el territorio no debe asumirse como algo diáfano, inmutable y definitivo puesto que no es posible aislar los sistemas, los objetos y las acciones de las prácticas cotidianas de los habitantes, cuyas relaciones sociales son capaces de producir/significar dicho territorio y este a su vez le da forma a esas relaciones, proyectando modos específicos de habitar como experiencia espacial de la vida cotidiana y su implicación en la configuración de identidades y de patrimonio colectivo que generan apegos, sentimientos y emociones en las personas (Fernandes, 2012; Zárate, 2016).

Precisamente, el habitar constituye una práctica cotidiana de sentido y significación al hecho de estar en el mundo (la experiencia de cohabitación), a la naturaleza espacial/territorial de la vida (la vida se hace en el espacio habitado-territorio) y a la relación dialéctica entre lo que hace y lo que es hecho (fricción entre lo instituido y lo instituyente al construir territorio) (Lazzarotti, 2015). En otras palabras, son los actos del habitar lo que les permiten a un individuo o grupo apropiarse del espacio y convertirlo en territorio a través de procesos de territorialización que condensan una relación geo-eco-antrópica en las prácticas de apropiación, organización y control del territorio por parte de los actores sociales quienes lo transforman e intervienen en él, definiéndolo y delimitándolo como su contexto/escenario de vida (Sosa, 2012), esto es, su hábitat.

A partir de esta dinámica cotidiana se configura un paisaje urbano que se transforma constantemente en términos de preferencias en cuanto a la adecuación de sus nichos estéticos ${ }^{2}$, la interacción social y la privacidad, la participación ciudadana y el sentido de identidad comunitaria, que se convierten en indicadores necesarios para que la sociedad reconozca en su territorio valores y elementos paisajísticos asociados con la cultura, las necesidades y las aspiraciones de quienes la integran.

En este sentido, se puede decir que la mezcla de los anteriores atributos sociales configura el bien cultural urbano como un patrimonio colectivo de la sociedad. Al respecto, el trabajo de Macarrón (2008)

\footnotetext{
${ }^{1}$ El turismo es un elemento funcional del fenómeno urbano, cuya dinámica crea "no lugares" expuestos como espacios funcionales, sin identificación y por fuera de la historia, reducido al consumo del público que colecciona este tipo de escenarios (Augé, 1993).

${ }^{2}$ Silva (2014) afirma que la estética social es capaz de crear nuevas ambientaciones entre ciudadanos cuya intención es adecuar el entorno a sus intereses y/o necesidades. Como producto de estos procesos socioculturales se configuran nichos estéticos o casas transitorias que pueden figurar como estrategia política, combate (resistencia), resguardo y/o proyección de las acciones que le dan sentido a la experiencia ciudadana.
} 
expone que la sociedad actual se caracteriza por haber tomado conciencia del valor de los bienes culturales como patrimonio colectivo, universal en algunos casos, reconociéndose heredera pero también depositaria y responsable, esto conlleva a respetar sus cualidades materiales, estéticas, históricas y documentales para mantener al máximo la entereza de sus significados auténticos y originales, vinculados a las percepciones y usos del espacio habitado y al sentido de pertenencia como expresión, según Yory (2007), de los lazos afectivos (sentimientos positivos) que se construyen entre las personas y los lugares específicos que habitan.

\section{Aspectos metodológicos}

Este estudio se abordó mediante un enfoque mixto que supone la combinación sinérgica y complementaria entre los aspectos cualitativos y cuantitativos en la recogida y análisis de los datos desde una perspectiva amplia y profunda del fenómeno por medio de un diseño explicativo secuencial que permitió interpretar, explicar y profundizar los hallazgos en los datos obtenidos de la aplicación de la encuesta (Hernández et al., 2014) en los municipios costeros de Moñitos y San Bernardo del Viento al norte del Departamento de Córdoba, Colombia (Figura 2).
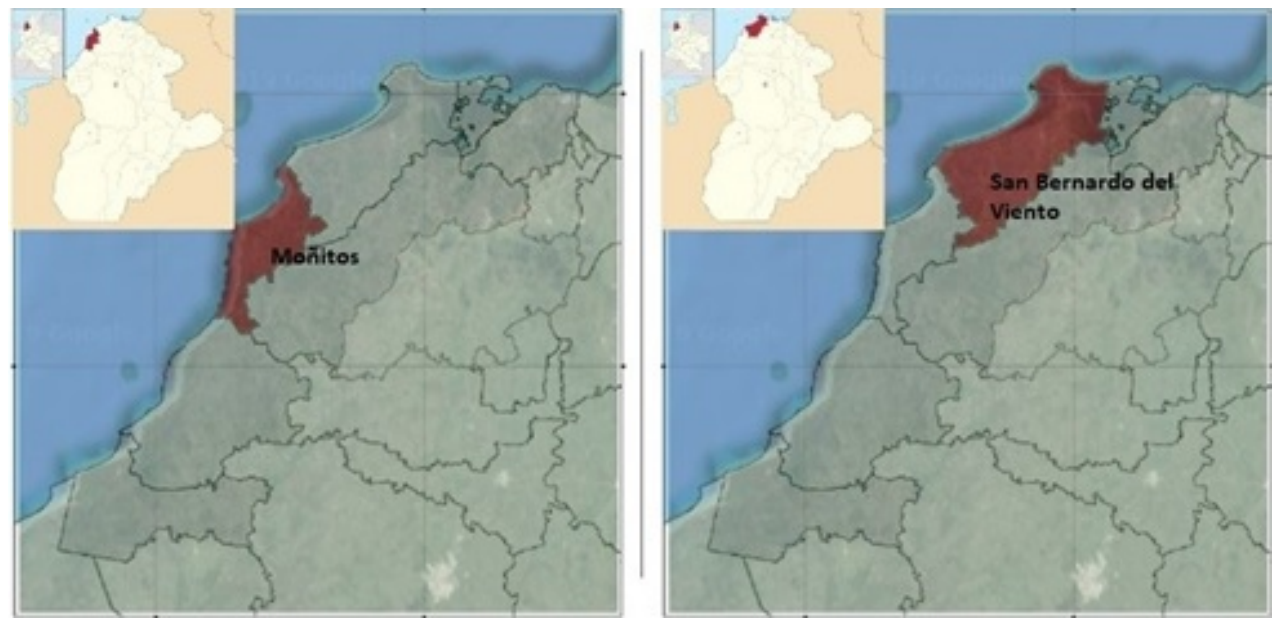

Figura 2 - Ubicación de los municipios costeros al norte del Departamento de Córdoba. Fuente: Elaboración propia (2019).

Para la identificación de las particularidades físicas, históricas y socioculturales del territorio y los modos de denominar el mundo urbano a partir de las cualidades/calificaciones/escenarios signados por las personas que lo habitan, se empleó la encuesta de imaginarios urbanos de Silva (2004) que funciona como una entrevista cuyas preguntas son de naturaleza subjetiva y que exploran las emociones de los ciudadanos que se derivan del proceso de consolidación del hábitat mediado por los actos del habitar. Este instrumento consta de 82 preguntas distribuidas en cuatro áreas: identificación, ciudad, ciudadanos y otredades (percepción desde otras ciudades); no obstante, para el desarrollo de esta investigación solo se tuvo en cuenta la categoría de ciudad en la cual se agruparon las referencias al lugar en su sentido físico e histórico con el propósito de revelar las calidades identificatorias de la atmósfera urbana costera del Departamento de Córdoba.

La población del estudio estuvo constituida por 16.151 personas que habitan el área urbana en ambos municipios costeros, considerando una muestra intencional de 100 (50 personas por cada municipio). Esta selección se realizó teniendo en cuenta los criterios de antigüedad de los habitantes (preferentemente nacidos en el lugar), edad (16 años en adelante) y estrato social; con el fin de garantizar procesos identitarios, relacionales e históricos de los actores sociales dentro de su hábitat (Vega Martínez et al., 2019a) y desplegados en el habitar que produce y transforma el espacio. Los datos 
obtenidos a partir de la aplicación de la encuesta fueron tabulados y diagramados por medio de las herramientas del programa Microsoft Excel 2010.

\section{El habitar en lugares tranquilos y llenos de alegría}

Teniendo en cuenta los resultados, ambos municipios se destacan como zonas de contradicciones urbanas, por un lado, las personas definen a sus municipios como lugares tranquilos, llenos de alegría y con vocación turística, cuyas concepciones se encuentran arraigadas al estilo de vida costero en la que ellos figuran ciudadanos anónimos y protagonistas de los procesos socioculturales intrínsecos en los actos del habitar (Figura 3). Por otro lado, se reconocen las necesidades urbanísticas de los municipios que hace que sus habitantes añoren que el progreso llegue a sus municipios y se traduzca en la transformación física de los mismos de tal manera que permita el desarrollo urbanístico de la zona al estilo de las grandes ciudades costeras, lo cual constituye un factor extrínseco que depende fundamentalmente de la voluntad política capaz de gestionar y liderar los cambios necesarios para lograrlo (Figura 4).

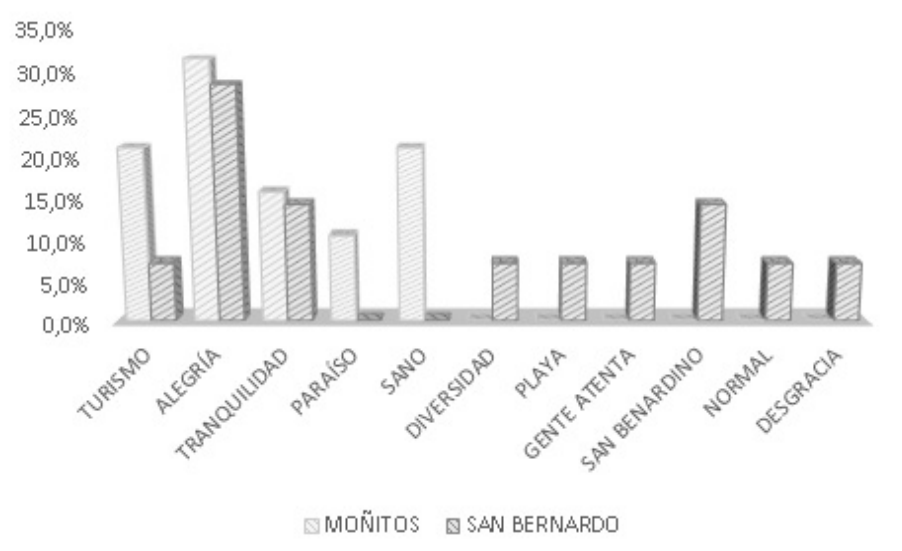

Figura 3 - Imagen o palabra con la que identifican las personas a Moñitos y San Bernardo del Viento. Fuente: Elaboración propia (2019).

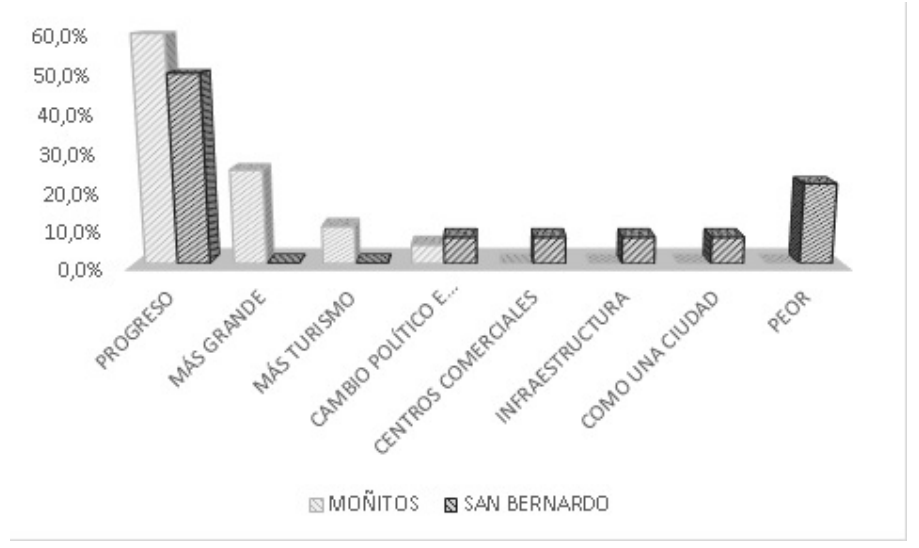

Figura 4 - Visualización a futuro de Moñitos y San Bernardo del Viento por sus habitantes. Fuente: Elaboración propia (2019).

Las apreciaciones expuestas por los habitantes de ambos municipios exponen prácticas socioculturales ligadas a una habitabilidad tradicional cuyos entramados significativos de interacción proyectan una dinámica de apropiación territorial vinculadas a la existencia de memorias, imágenes, símbolos, discursos y prácticas socialmente compartidas que se manifiestan en la cotidianidad de los 
habitantes del sector a partir de sus costumbres, anhelos y esfuerzos constantes por preservar su identidad (Vega Martínez et al., 2019a); y al mismo tiempo, mejorar sus condiciones de vida que se ven limitadas por las pocas fuentes de trabajo que ofrecen estos municipios, destacándose solo la agricultura, la pesca, el turismo y prácticas económicas informales como las ventas ambulantes y el mototaxismo. Es precisamente en lo cotidiano, a la deriva entre las actividades de subsistencia y la alegría que genera habitar en estos lugares, donde se configura el verdadero valor de sus particularidades que, en lo material, van tejiendo las estructuras socioculturales que permiten constituir un legado patrimonial en torno al mar como escenario representativo en el imaginario de las personas, el cual armoniza con la alegría plasmada en los oficios que se derivan del turismo y que se van amalgamando hasta constituirse en su herencia cultural y el lazo afectivo con su hábitat.

\section{Colores vinculados a la producción social del territorio}

Otra cualidad asociada al habitar de las personas en ambos municipios es la identificación de los colores azul y verde (Figura 5) como rasgos característicos que definen el entorno natural donde llevan a cabo sus prácticas cotidianas. El primero, se relaciona con la proximidad que existe entre la vida humana y el mar al ritmo de la tranquilidad que otorga este tipo de escenarios que propician la realización de actividades como la pesca y el turismo; sin embargo, esta relación con el mar es diferenciada entre los dos municipios a pesar de que el azul se encuentra en el imaginario de las personas como color predominante, mientras el emplazamiento urbano de Moñitos ocurre a orillas del mar, para San Bernardo del Viento las playas son un referente turístico que se encuentra a pocos kilómetros de la zona urbana y alrededor del cual se desarrolla actividades como el mototaximo (transporte público informal) y ventas ambulantes. Por su parte, el color verde como segunda opción es un complemento de la zona asociado al paisaje natural costero y al panorama tranquilo que brinda la arborización característica en estos espacios.

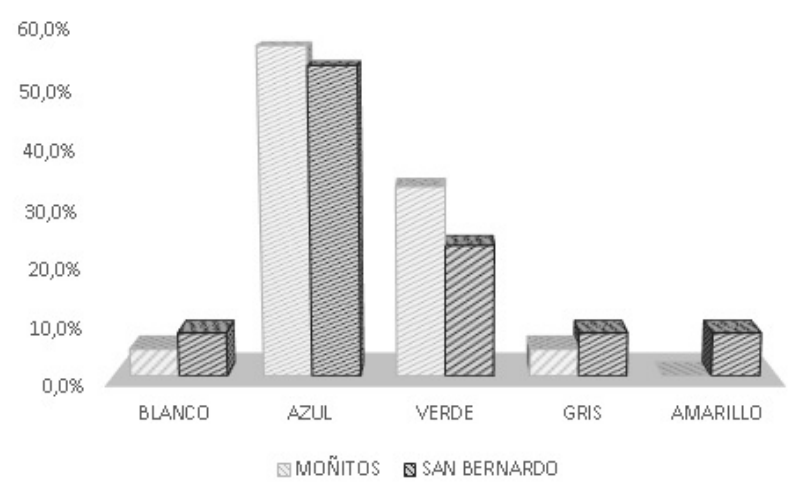

Figura 5 - Colores vinculados a la producción social del territorio en Moñitos y San Bernardo del Viento. Fuente: Elaboración propia (2019).

Desde esta perspectiva, la selección de los colores está determinada por el espacio natural donde se lleva a cabo la producción social del mismo caracterizado por ser alegre y tranquilo. Esto permite ver como la sublimación ${ }^{3}$ (adecuación) en estos municipios costeros armoniza con el entorno en la medida en que los colores referenciados por sus habitantes no desconocen la forma natural de un espacio que es polifuncional para las actividades humanas. Esta condición permite ver cómo lo urbano y las interrelaciones sociales en estos lugares constituyen un habitar que mantiene el paisaje y su biodiversidad y configura prácticas de habitabilidad tradicional que se ajustan al entorno, estos procesos

\footnotetext{
${ }^{3}$ Es un concepto socioantropológico que explica la capacidad de la vida humana para proyectar imágenes, figuras y representaciones producto de las motivaciones subjetivas, que orientan la existencia del hombre y facilitan su relación con el entorno natural (Sánchez, 1999).
} 
difieren de otras zonas costeras en Suramérica donde las actividades económicas como la minería y la industria inmobiliaria han aumentado la artificialización en la naturaleza costera y diversificado las prácticas sociales derivadas de la transformación del espacio social en constante conflicto (GuerreroCossio, 2016).

\section{"El olvido que somos"}

Si algo reconocen los habitantes de los municipios costeros son los problemas sociourbanos presentes en su hábitat en materia de déficit de infraestructura urbana (interna y externa), servicios públicos incompletos y altos niveles de desempleo en la región (Figura 6). A partir de estas apreciaciones, en el habitar se vincula como estrategia sociopolítica de representación y apropiación del territorio dos actividades económicas informales importantes como lo son las ventas ambulantes y el mototaxismo (transporte informal), las cuales dependen fundamentalmente del turismo en las playas y se establecen como un mecanismo de sobrevivencia y desarrollo propio de las personas en estos lugares (Figura 7).

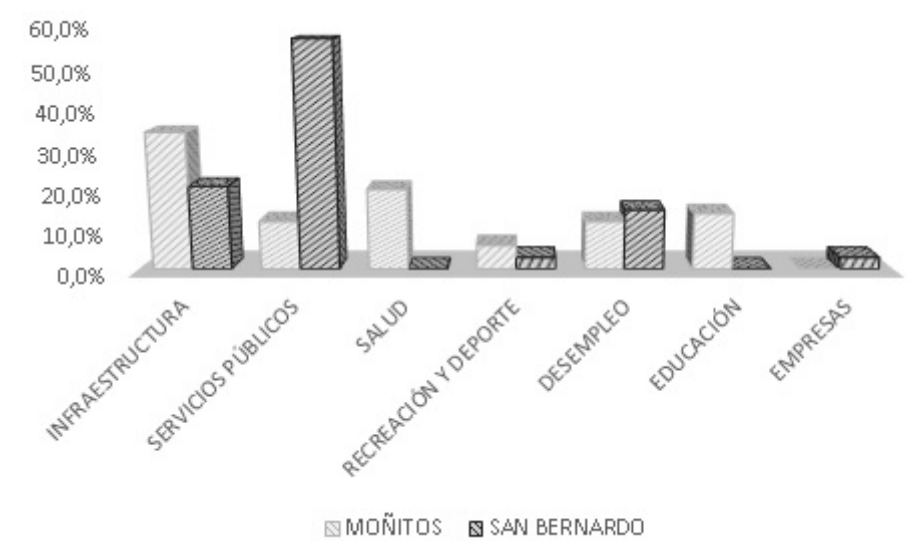

Figura 6 - Problemas sociourbanos vinculados al habitar en Moñitos y San Bernardo del Viento. Fuente: Elaboración propia (2019).

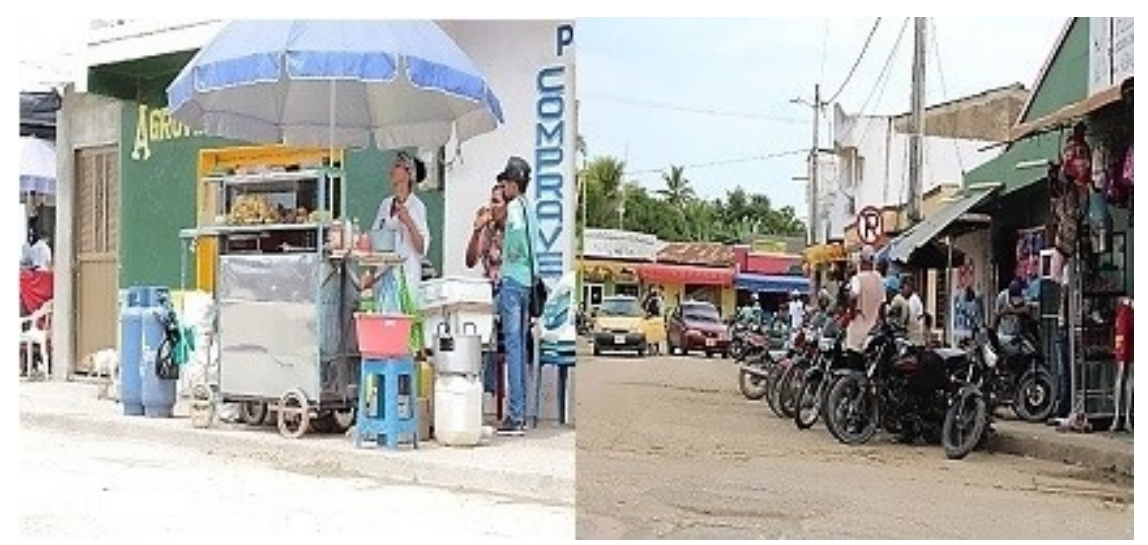

Figura 7 - Las ventas ambulantes y el mototaxismo como estrategia sociopolítica asociada al habitar en los municipios costeros. Fuente: Elaboración propia (2019).

Esta situación coincide con lo expuesto por Hidalgo et al. (2016) al manifestar que los problemas sociourbanos en estos asentamientos radican en las fragilidades de la planificación urbana que en muchos casos son atemporales y distantes de las demandas ciudadanas; es por ello que, Barbera et al. (2018) conscientes de que la planificación se enfrenta a una naturaleza incierta, inestable y no - lineal, debe apuntar al desarrollo sostenible a partir de la valoración multidimensional del espacio en uso/usado 
o territorio. Por otra parte, esta realidad sociourbana pone de manifiesto el olvido estatal a la que son sometidas estas localidades que se encuentran en riesgo de vulnerabilidad por la exclusión y la desigualdad, producto del crecimiento descontrolado y la falta de planificación urbana (Vega Martínez et al., 2019b). De ahí que, los nichos estéticos en ambos municipios se encuentran adecuados a lo que el entorno les ofrece expuesta en el mar como fortaleza y motor turístico de la zona, a partir de la cual despliegan sus prácticas socioculturales, económicas y políticas, a pesar de las inconformidades en materia del déficit de infraestructura y servicios públicos que presentan estos municipios costeros.

\section{Fricciones sociales costeras}

Como quiera que los imaginarios constituyen la realidad para las personas, se pueden identificar dos escenarios que generan fricciones entre lo percibido y las características del espacio sociourbano, vinculadas al rezago urbano de la zona costera del departamento de Córdoba. En primer lugar, se puede identificar la tensión lugares visualizados con progreso y desarrollo urbanístico versus déficit de equipamiento urbano (Figura 8): para los ciudadanos su cultura urbana gira a procesos de representación y apropiación territorial motivados por el deseo de aprovechar la ventaja competitiva que les proporciona el espacio en uso/usado en función del turismo como principal motor económico que permita un crecimiento y desarrollo urbano mediante la movilidad de recursos y la gestión de proyectos de infraestructura; no obstante, este sentipensar entra en choque con las necesidades urbanas que presentan estos municipios asociadas a la falta de inversión en infraestructura y mejoramiento de los servicios públicos. Para los habitantes de ambos municipios existe un malestar en cuanto al rezago y el olvido en el que están sus municipios aun cuando se consideran a sí mismos como potencia turística en el departamento, por esta razón, el colectivo social reclama una intervención administrativa a nivel municipal y regional que permita mejorar el nivel de vida en estas zonas.

En segundo lugar, otra fricción social está relacionada con la tranquilidad que caracteriza los lugares versus la informalidad económica y los altos índices de desempleo. En el imaginario de la gente está presente que su fortaleza económica es el turismo como atractivo de sus lugares autodenominados como paraísos, tranquilos y amables; a pesar de esto hay un reconocimiento de los problemas que enfrentan sus comunidades relacionados con una característica propia de la realidad regional y nacional, como lo es el desempleo, reflejado en las ventas ambulantes y el mototaxismo principalmente. Este reconocimiento es un indicador de que las personas desean que sus municipios progresen y mejoren sus condiciones en materia de equipamiento y conexión intermunicipal para promover la reactivación de la economía.
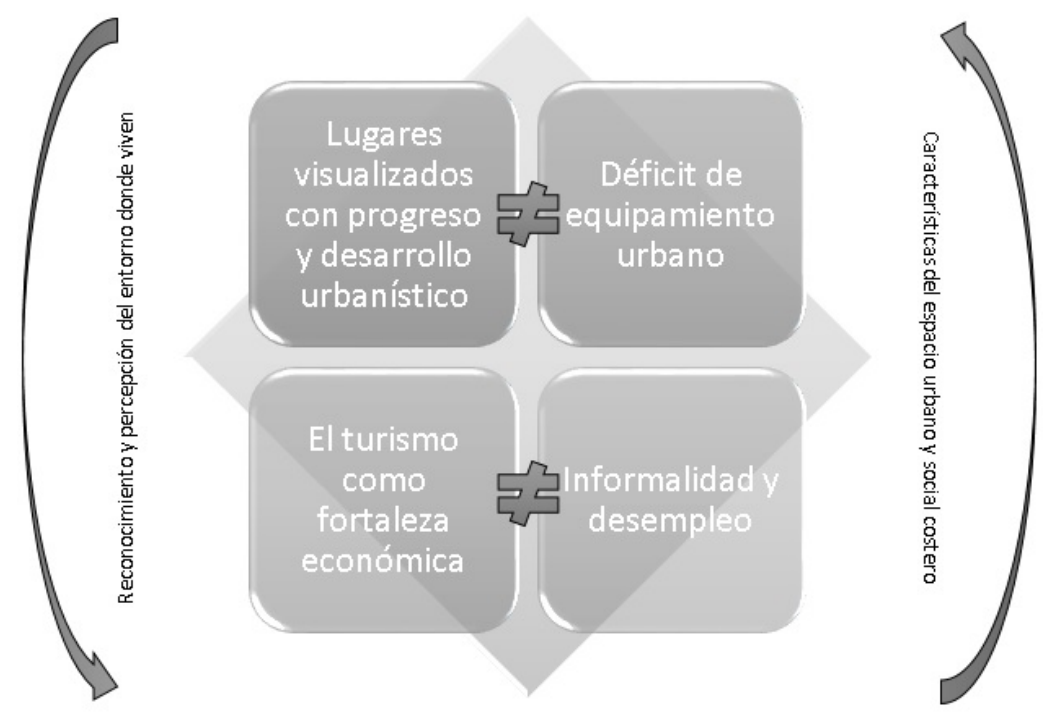

Figura 8 - Fricciones sociales en los municipios costeros. Fuente: Elaboración propia (2019). 


\section{Conclusiones}

Los procesos de territorialización en estos municipios costeros han sido lentos, la percepción del entorno donde viven y proyectada en el habitar por sus pobladores permite identificar una especie de fragmentación urbana al considerar que sus municipios se encuentran casi que aislados espacial y territorialmente (déficit de equipamiento urbano). Este fenómeno según Escolano-Utrilla et al. (2018) se relaciona con la globalización económica y cultural que se expresa en múltiples formas de estructuración social, en el fraccionamiento de la política y gobernanza de las ciudades y en la segmentación física y funcional del territorio construido, que a nivel departamental se evidencia en el aislamiento de sus territorios con respecto a la capital (Montería) y a nivel interno en los municipios costeros se reconoce que carecen de una organización política y urbana capaz de potencializar su vocación turística, cultural y natural presente en los ecosistemas que brindan los bordes costeros.

Estos lugares bien pueden servir de ejemplo para la diversidad urbana vista desde el habitar, esto es, los diversos modos en que se vive e intenta habitar lo urbano que, en el caso costero del Departamento de Córdoba muestra procesos de hibridación entre el entorno natural y la producción social del territorio en estos ecosistemas donde se revelan formas de urbanización que requieren ser gestionadas a partir de las necesidades que comunican quienes viven en estos lugares, relacionadas según Costa et al. (2019) con el acceso a los servicios urbanos y la incapacidad para generar recursos y reinversión local que permita mejorar la calidad de vida de la población que no es visible para los responsables políticos.

De igual forma, los resultados de este estudio sirven de referente para entender las dinámicas urbanas de ciudades pequeñas que, a pesar de sus problemas sociourbanos, buscan integrarse territorialmente e insertarse en las economías regionales y nacionales a partir de diversas estrategias sociopolíticas de representación y apropiación territorial que se vinculan en el habitar y permiten proveerse de bienes y servicios que se encuentran en el ecosistema al cual se adscriben (philia-ción) emocionalmente como sociedad.

\section{Referencias}

Álvarez Abel, R., \& Ther Ríos, F. (2016). Fragmentos de una cosmovisión mestiza asociada al acceso y uso del entorno costero en el archipiélago de Chiloé. Diálogo Andino, (49), 123-129. http://dx.doi.org/10.4067/S071926812016000100014.

Augé, M. (1993). Los no lugares: espacios del anonimato. Barcelona: Gedisa.

Barbera, N., Payares, L., Camejo, L., \& Chirinos, Y. (2018). Matices de la planificación del desarrollo sostenible desde la complejidad. In Y. Chirinos, A. Ramírez, N. Barbera, L. Camejo, \& V. Meriño (Eds.), Tendencias en la Investigación Universitaria: una visión desde Latinoamérica (Vol. II, pp. 94-113). Venezuela: Fondo Editorial Universitario Servando Garcés de la Universidad Politécnica Territorial Alonso Gamero.

Costa, S., Carmo, M., \& Barja, P. (2019). The urban hierarchy at the delta of the Amazon River and the importance of small cities. urbe. Revista Brasileira de Gestão Urbana, 11, e20180014. http://dx.doi.org/10.1590/21753369.011.001.ao09.

Escolano-Utrilla, S., López-Escolano, C., \& Pueyo-Campos, Á. (2018). Urbanismo neoliberal y fragmentación urbana: el caso de Zaragoza (España) en los primeros quince años del siglo XXI. EURE. Revista Latinoamericana de Estudios Urbano Regionales, 44(132), 185-212. http://dx.doi.org/10.4067/s0250-71612018000200185.

Fernandes, B. (2012). Disputas territoriales entre el campesinado y la agroindustria en Brasil. Cuadernos del CENDES, 29(81), 1-22.

Gravano, A. (2016). Antropología de lo urbano. Santiago de Chile: LOM Ediciones. 
Guerrero Valdebenito, R. M., \& Alarcón Rodríguez, M. (2018). Neoliberalismo y transformaciones socio-espaciales en caletas urbanas del Área Metropolitana de Concepción: los casos de Caleta Los Bagres y Caleta Cocholgüe, Tomé. Revista de Urbanismo, 38(38), 1-17. http://dx.doi.org/10.5354/0717-5051.2018.48666.

Guerrero-Cossio, V. (2016). Las recientes transformaciones en Iquique: el nuevo sujeto costero. Norte de Chile. Diálogo Andino, (51), 73-80. http://dx.doi.org/10.4067/S0719-26812016000300073.

Hernández Araque, M. J. (2016). Urbanismo participativo: construcción social del espacio urbano. Revista de Arquitectura, 18(1), 6-17. http://dx.doi.org/10.14718/RevArq.2016.18.1.2.

Hernández, R., Fernández, C., \& Baptista, P. (2014). Metodología de la investigación (6th ed.). México: McGraw Hill. Hidalgo, R., Alvarado, V., Arenas, F., Salazar, A., \& Volker, P. (2016). La comunidad disidente: reacción, métodos y conflictividad socio-espacial en el borde costero de la Región de Valparaíso. ACE: Architecture, City and Environment, 10(30), 31-56.

Lazzarotti, O. (2015). L'«habiter», sur un plateau. Annales de Géographie, 704(4), 335-337. http://dx.doi.org/10.3917/ag.704.0335.

Lefebvre, H., \& Lorea, I. (2013). La producción del espacio (pp. 31-50). Madrid: Capitán Swing. Macarrón, A. (2008). Conservación del patrimonio cultural: criterios y normas. Madrid: Síntesis.

Martí-Ciriquián, P., \& García-Mayor, C. (2018). Frentes marítimo-fluviales en ciudades españolas: nuevos espacios urbanos. Bitácora Urbano Territorial, 28(3), 71-79. http://dx.doi.org/10.15446/bitacora.v28n3.72186.

Martínez, C., Rojas, C., Rojas, O., Quezada, J., López, P., \& Ruíz, V. (2016). Crecimiento urbano sobre geoformas costeras de la llanura de San Pedro, Área Metropolitana de Concepción. In R. Hidalgo, D. Santana, V. Alvarado, F. Arenas, A. Salazar, C. Valdebenito, \& L. Álvarez (Eds.), En las Costas del Neoliberalismo. Naturaleza, Urbanización y Producción inmobiliaria (Colección Geolibros, pp. 287-312). Chile: Instituto de Geografía, Pontificia Universidad Católica de Chile.

Rionda, J. (2008). Pensar la ciudad desde la óptica del territorio. Urbano, 11(17), 76-82. Recuperado el 16 de diciembre de 2019, de http://revistas.ubiobio.cl/index.php/RU/article/view/365/328

Rubilar, L. (2015). Valoración de los paisajes urbanos del borde costero central. Una estrategia para rescatar su identidad. Caso: Cartagena-Región de Valparaíso-Chile (Tesis doctoral). Universidad de Sevilla, Sevilla, España.

Sánchez, C. (1999). Imaginación y sociedad: una hermenéutica creativa de la cultura. Madrid: Editorial Tecnos, S.A.

Santos, M. (2000). La naturaleza del espacio. Barcelona: Editorial Ariel.

Silva, A. (2000). Imaginarios urbanos, Bogotá y São Paulo: cultura y comunicación urbana en América Latina. Bogotá: Tercer Mundo Editores.

Silva, A. (2004). Imaginarios urbanos: hacia el desarrollo de un urbanismo desde los imaginarios. Metodología. Bogotá: Convenio Andrés Bello, Universidad Nacional de Colombia.

Silva, A. (2014). Atmósferas ciudadanas: grafiti, arte público, nichos estéticos. Bogotá: Universidad Externado de Colombia.

Sosa, M. (2012). Cómo entender el territorio? Guatemala: Cara-Parens.

Tuirán, A., De la Rosa, I., \& Mercado, A. (2018). Gobernabilidad local en el departamento de Córdoba. Barranquilla: Observatorio de Gobernabilidad Local, Centro de Pensamiento UNcaribe, Universidad del Norte. http://dx.doi.org/10.13140/RG.2.2.30699.80164.

Vega Martínez, A. A., Hernández Buelvas, E. J., \& Barbera Alvarado, N. (2019a). Configuración territorial del hábitat en el asentamiento informal Alfonso López de la ciudad de Montería-Colombia. Revista INVI, 34(97), 81-103. http://dx.doi.org/10.4067/S0718-83582019000300081.

Vega Martínez, A. A., Hernández Buelvas, E. J., \& Mestra Padilla, C. C. (2019b). Cultura urbana a partir de los imaginarios sociales en el asentamiento informal El Níspero de la ciudad de Montería, Colombia. In Y. Chirinos, A. Ramírez, N. Barbera, \& D. Rojas (Eds.), Tendencias en la Investigación Universitaria: una visión desde Latinoamérica 
(Vol. V, pp. 101-117). Venezuela: Fondo Editorial Universitario Servando Garcés de la Universidad Politécnica Territorial Alonso Gamero.

Yory, C. (2007). Del espacio ocupado al lugar habitado: una aproximación al concepto de topofilia. Revista Barrio Taller, 12, 56.

Zárate, M. (Ed.). (2016). Paisajes culturales a través de casos en España y América. Madrid: UNED.

Editor: Rodrigo Firmino

Recibido: Dic. 16, 2019

Aprobado: Ago. 06, 2020 